\title{
WORKING FROM HOME DURING THE COVID-19 PANDEMIC: WHAT IS THE IMPACT ON EMPLOYEES' PSYCHOLOGICAL MEANINGFULNESS, SAFETY, AND AVAILABILITY?
}

\author{
Siti Fani Daulay; Martina Dwi Mustika ${ }^{2 *}$ \\ ${ }^{1,2}$ Applied Psychology of Human Resource, Faculty of Psychology, University of Indonesia \\ Jl. Lkr. Kampus Raya J1. Mawar No. 538, Pondok Cina, Depok, Jawa Barat 16424, Indonesia \\ ${ }^{1}$ sitifanidaulay@gmail.com; ${ }^{2}$ martinadwimustika@gmail.com
}

Received: $18^{\text {th }}$ February 2021/ Revised: $23^{\text {rd }}$ May 2021/ Accepted: $31^{\text {st }}$ May 2021

\begin{abstract}
How to Cite: Daulay, S. F. \& Mustika, M. D (2021). Working from home during the COVID-19 pandemic: What is the impact on employees' psychological meaningfulness, safety, and availability?. Humaniora, 12(3), $233-241$.

https://doi.org/10.21512/humaniora.v12i3.7062
\end{abstract}

\begin{abstract}
The research aimed to explore the relation of work-home and home-work interactions on employees' psychological condition while working from home during the COVID-19 pandemic. The coronavirus (COVID-19) pandemic had led various organizations to implement work-from-home measures. This rapid change in working arrangements might affect employees' psychological condition as they navigate both their work and home responsibilities at the same time and place. The research involved 2.288 employees at one government institution in Indonesia. Data were collected in April 2020, using the web-based tool Survey Monkey. The data were analyzed by logistic regression analysis. The results show that Negative Work-Home Interactions (NWHI) are significantly associated with psychological meaningfulness and psychological safety, while Negative Home-Work Interactions (NHWI) are significantly associated with the three psychological dimensions. Positive Work-Home Interactions (PWHI) are significantly associated with psychological safety, while Positive Home-Work Interactions (PHWI) are significantly associated with the three psychological dimensions. Based on the results, it can be concluded that positive and negative experience that happens at work spill over to the home domain and vice versa, which could, in turn, impact on employee sense of meaningful, safety, and sense of having the physical, emotional, and psychological resources to perform tasks at work during working from home. Therefore, organizational support is important in maintaining employees' psychological condition while working from home during the pandemic.
\end{abstract}

Keywords: work-from-home, COVID-19 pandemic, psychological meaningfulness, emplyoyee safety, employee availability

\section{INTRODUCTION}

In March 2020, the World Health Organization (WHO) declared the coronavirus (COVID-19) a global pandemic following its rapid spread across the world. By February 2021, there had been 102.399.513 confirmed cases of COVID-19 worldwide, including 2.217.005 deaths (WHO, 2021). Almost all countries worldwide have implemented measures such as lockdown, quarantine for regions with a high number of cases, closing schools, and travel restrictions to slow down the spread of the COVID-19 outbreak (Atalan, 2020). The coronavirus not only leads to physical health risks but also impacts on the mental health of an individual at the workplace, as they are unable to engage in their normal daily activities and see family, friends, or colleagues (Abrams, 2020; APS, 2020; WHO, 2020). Due to its highly contagious nature, many private and government organizations seek alternative work arrangements such as working from home to be implemented during pandemics (ILO, 2020). Such new policies, as well as the pandemic itself, create uncertainty.

As most employees are now experiencing new alternative ways of working, it is expected that their current and previous experiences will differ. Following 
the implementation of work from home measures, employees also must take care of themselves and their families while working at the same time and in the same place, which may create further psychological strain. This uncertainty can have a major impact on their psychological condition, which will affect their performance at work (Vyas \& Butakhieo, 2020; Xiao et al., 2021). During this uncertain period, organizations should pay attention to employees' psychological condition because it is closely related to employee engagement and significantly affects mental health in the workplace (Kahn, 1990; May, Gilson, \& Harter, 2004; Rothmann \& Baumann, 2014).

Psychological conditions define as psychological experiences of the rational and unconscious elements of work context that influence employee attitude and behavior (Kahn, 1990). The work context, mediated by people's perception, creates conditions in which employees personally engage and disengage with their work. If certain conditions are met to an acceptable degree, employees tend to engage more in their work, driven by their internal motivation and vice versa (Kahn, 1990).

As a multidimensional concept, Kahn (1990) has identified three dimensions of the psychological conditions: psychological meaningfulness, psychological safety, and psychological availability. Psychological meaningfulness is associated with work elements that create a feeling of usefulness and worth based on employees' investment in their work (Kahn, 1990). Employees experience such meaningfulness when their work facilitates personal growth and motivation (Kahn, 1990; May, Gilson, \& Harter, 2004). High psychological meaningfulness is characterized by feeling that inseparable from their work, commitment, more involved, and are likely to be motivated to spend time and effort more fully in their roles at work (Cai et al., 2018; Fairlie, 2011; May, Gilson, \& Harter, 2004). On the other hand, lack of meaningfulness can lead to disengagement from work (Kahn, 1990; May, Gilson, \& Harter, 2004).

Psychological safety is associated with elements of social systems that create a sense of being able to show and apply oneself without fear of negative consequences to self-image, status, or career prospects (Kahn, 1990). Employees are more likely to feel safe when they perceive that situations are trustworthy, secure, and predictable (Kahn, 1990; May, Gilson, \& Harter, 2004). This safety allows employees to interact without shyness or low self-esteem, motivated to sustain positive behavior such as openness and self-expression (Cai et al., 2018; Kahn, 1990). While employees perceive unsafe conditions when situations are ambiguous, unpredictable, and threatening (May, Gilson, \& Harter, 2004).

The third psychological condition, psychological availability, refers to the sense of having the physical, emotional, and psychological resources to perform tasks at work (Kahn, 1990). Employees are more or less available to engage in their work depending on the way they cope with the various demands of work and the personal aspects of their lives (Kahn, 1990). High availability reflects the readiness and effectiveness of employees at work; they have confidence and a clear mind in completing the task (Cai et al., 2018; Kahn, 1990).

Several factors influence the three dimensions of the psychological condition, including both individual and situational factors. According to Kahn (1990), three factors generally contribute to psychological meaningfulness: task characteristics (e.g., autonomy and variety), role characteristics (e.g., role fit), and work interactions (e.g., supervisor support). May, Gilson, and Harter (2004) have shown that job enrichment and work role fit are related to psychological meaningfulness. Meanwhile, psychological safety is influenced by interpersonal relationships, group and intergroup dynamics, management style, processes, and organizational norms (Kahn, 1990). Kahn (1990) has further identified psychological availability factors as issues involving workplace distractions; employees' personal lives; depletion of physical, emotional, and cognitive energy; and individual insecurity.

During the pandemic, employees change their way of working to teleworking. Teleworking is an alternative work arrangement that allows employees to work away from centrally located offices and use electronic media to communicate with others inside and outside their organization (Chong, Huang, \& Chang, 2020; Oakman et al., 2020).

Previous research has shown that teleworkers tend to experience a better work-life balance because they have more time and control over the ability to balance work with family obligations (Grant, Wallace, \& Spurgeon, 2013; Thulin, Vilhelmson, \& Johansson, 2019). However, working from home is also associated with blurring the boundaries between home and work life because employees must navigate both their work and home responsibilities simultaneously and in the same place (Palumbo, 2020; Solís, 2016). During the ongoing COVID-19 pandemic, changes to the nature of work, increasing demands for working from home, and rapid role change are likely to impact employee interactions at work and home (Jostell \& Hemlin, 2018; Vaziri et al., 2020).

Some work-related and organizational factors play a crucial role in influencing psychological conditions. One of which is interactions between work and home domain. The impact of these interactions depends on the direction (work affects home versus home affects work) and the quality (negative versus positive) of influence (Geurts et al., 2005).

Although prior research has demonstrated an effect of work-home interactions on three psychological dimensions (Łaba \& Geldenhuys, 2018; Rothmann \& Baumann, 2014), the research seeks to further explore whether the results of previous research are applicable in the context of working from home during the present ongoing pandemic. To do so, the research aims to investigate the association between work-home interactions with the three psychological dimensions: psychological meaningfulness, psychological safety, 
and psychological availability.

Geurts et al. (2005) have defined work-home/ home-work interactions as an interactive process in which one's functioning and behavior in one domain (e.g., home) are influenced by negative or positive load reactions that have built up in the other domain (e.g., work). Four types of interaction can be distinguished based on this definition (Demerouti, Geurts, \& Kompier, 2004; Geurts et al., 2005); first, Negative Work-Home Interactions (NWHI) refers to situations in which negative load effects build up at work and hamper one's functions at home. Second, Negative Home-Work Interactions (NHWI) refers to negative load effects that build up in home situations and hamper one's functions at work. Third, Positive Work-Home Interactions (PWHI) refers to situations in which positive load reactions develop at work facilitate one's functions at home. Fourth, Positive Home-Work Interactions (PHWI) is defined as positive load reactions that build-up at home and facilitate one's work functions.

The assumption that work affects the way an individual functions at home and vice versa can be explained regarding effort-recovery theory (Demerouti, Bakker, \& Voydanoff, 2010; Geurts et al., 2005). When effort investment in one domain becomes excessive (e.g., a high-pressure job, excessive job demands, or parental work overload) and recovery opportunities are insufficient, a negative-load reaction may spill over to the other domain. In the same sense, if an individual has sufficient resources for recovery, they tend to exhibit a positive-load reaction, which in turn enables them to function in their role.

Both positive and negative work-home/homework interactions are influenced by several individual factors, such as gender, age, personality, and affect state (Hill \& Blunn, 2018; Paulson \& Leuty, 2016), as well as situational factors arising from the work domain such as job demand, job control, supervisor support (Carvalho et al., 2018), and family domains such as home pressure, home resource (e.g., family member's involvement, income), parental status and children (Geurts et al., 2005; Michael-Tsabari et al., 2020). Previous research has shown that interactions between work and the home influence job performance, well-being, and employee engagement (Demerouti, Bakker, \& Voydanoff, 2010; Rothmann \& Baumann, 2014; Verweij et al., 2017).

The literature on work and family has shown an association between some types of work-home interactions and psychological conditions. Previous studies have shown that employees who experience negative work-home interactions are likely to experience less psychological meaningfulness at work (Rothmann \& Baumann, 2014), as well as a negative impact on their psychological safety (Obrenovic et al., 2020), which subsequently prevents them from being available for their roles (Rothmann \& Baumann, 2014). Conflict associated with family and work responsibilities also reduces employee availability because both person- and work-related conflict can lead to employee distraction, which reduces the amount of energy they have available to invest in other roles (Kahn, 1990). Elsewhere, positive workhome interactions have been shown to be positively associated with psychological meaningfulness (Munn, 2013; Rothmann \& Baumann, 2014), psychological availability ( Laba \& Geldenhuys, 2018; Rothmann \& Baumann, 2014), and also improve employees' level of confidence in participating in the workplace (Mostert, 2006).

Based on these discussions, the hypotheses are proposed: (1) Negative work-home and homework interactions have a negative association with psychological meaningfulness, (2) Negative workhome and home-work interactions have a negative association with psychological safety, (3) Negative work-home and home-work interactions have a negative association with psychological availability, (4) Positive work-home and home-work interactions have a positive association with psychological meaningfulness, (5) Positive work-home and homework interactions have a positive association with psychological safety, and (6) Positive work-home and home-work interactions have a positive association with psychological availability.

\section{METHODS}

The research is conducted at one government institution in Indonesia. Participants are employees that implement work from home measures during the COVID-19 pandemic. Their participation is voluntary. All respondents are given detailed informed consent to guide their participation. They are assured that participation in the research is anonymous to ensure confidentiality. The research has received ethical clearance from the Faculty of Psychology and is supported by the head of the human resource department from the participating organization. The organization sends an official invitation letter to all employees to participate in the research voluntarily. Data are collected in April 2020 using the web-based tool SurveyMonkey. The questionnaire is distributed by email to all employees. As an online survey tool, the use of SurveyMonkey allows the researchers to automatically randomize all questions on each page to minimize common method bias (Podsakoff, MacKenzie, \& Podsakoff, 2012). The researchers also used attention checks to identify careless respondents and exclude them before conducting the analysis (Kung, Kwok, \& Brown, 2018).

Of the total 2.740 participants who have completed the questionnaire, 452 responses are eliminated from the analysis, including incomplete answers. As a result, there are 2.288 participants in this research $(M A g e=39,7$, SDAge $=77,45)$. At least $11,3 \%$ of the participants are aged $15-25$ years, $64 \%$ are aged $25-44$ years, $18,4 \%$ are aged $45-64$ years, and $6,5 \%$ are 65 years old or more. Of the participants, $50,3 \%$ are male, and $49,7 \%$ are female. In terms of 
education, $9 \%$ of the participants have finished high school or the equivalent, $11 \%$ have obtained an undergraduate degree, $62,5 \%$ have obtained a master's degree, and $18 \%$ have received a postgraduate degree as their latest educational qualification.

There are two questionnaires used to measure the variable in the research: psychological conditions and the work-home interaction scales. All scales use a 4-point Likert scale ranging from 1 (never) to 4 (always). All questionnaires are translated and adapted in Indonesian based on the translation guidelines by ITC (2017).

Psychological conditions are measured using the Psychological Conditions Scale developed by May, Gilson, \& Harter (2004) based on Kahn's (1990) theoretical framework. The questionnaire consists of 14 items that assess three dimensions of psychological conditions, namely, psychological meaningfulness (six items), psychological safety (three items), and psychological availability (five items). As a multidimensional variable, the researchers have summed the item scores for each dimension and the total score for each dimension serving as a unidimensional variable for psychological conditions.

To ensure internal consistency of measurement, the researchers calculate the Cronbach's alpha for all variables. The coefficient alpha for psychological conditions as unidimensional variables shows good internal consistency $(\alpha=0,90)$. The following describes the measurement and alpha coefficient for each dimension. Psychological meaningfulness measures the degree of meaning that employees discover in their work-related activities (May, Gilson, \& Harter, 2004). An example item for psychological meaningfulness, "My job activities are personally meaningful to me." The coefficient alpha is 0,93 . Psychological safety measures the degree to which employees feel comfortable being themselves, expressing their opinions, and feeling safe in the existing work environment (May, Gilson, \& Harter, 2004). An example item for psychological safety, "I am not afraid to be myself at work." This scale shows low reliability $(\alpha=0,51)$. Psychological availability measures the extent to which employees believe that they can be available cognitively, physically, and emotionally for work. An example item for psychological availability, "I am confident in my ability to handle competing demands at work." (May, Gilson, \& Harter, 2004). The coefficient alpha is 0,80 .

Work-home interactions are measured using the Survey Work-Home Interaction-Nijmegen (SWING) developed by Geurts et al. (2005). The SWING consists of 22 items that assess four types of interactions between work and home, namely, NWHI (eight items), NHWI (four items), PWHI (five items), and PHWI (five items). The total score for each dimension is generated by averaging each item.

An example item for NWHI is, "I am irritable at home because my work is demanding." The coefficient alpha is 0,86 . An example item for NHWI is, "I do not feel like working due to problems with my spouse/ family/friends." The coefficient alpha is 0,69 . An example item for PWHI is, "After a pleasant working day/working week, I feel more in the mood to engage in activities with my spouse/family/friends." The coefficient alpha is 0,69 . An example item for PHWI is, "I manage my time at work more efficiently because at home I must do that as well." The coefficient alpha is 0,77 .

The data are analyzed using SPSS version 26. No missing values are imputed. Logistic regression analysis is used to test for associations between work-home interactions on psychological conditions. Work-home interactions are used as the continuous variables. Responses for each psychological condition dimension are scored and dichotomized into the group of high and low according to the cut-off score. The mean and standard deviation of the scale is used as a cut-off point to categorize high and low psychological conditions. The percentage for each category is reported in Table 1. The goodness of fit is determined based on the Hosmer-Lemeshow (H-L) test (see Table 3 ). All three models yield an insignificant p-value $(>0,05)$, which indicates that the model fits the data (Hosmer \& Nils, 2002).

\section{RESULTS AND DISCUSSIONS}

Table 1 shows that most participants are classified as having high-psychological conditions, as well as the three dimensions of psychological meaningfulness, psychological safety, and psychological availability. While Table 2 shows the means, standard deviation, and correlation for all variables in the research. The results show that most variables are significantly either positively or negatively correlated with each other.

Table 3 provides the result of logistic regression for all variables. The odds ratios (ORs), p-values, and Nagelkerke Pseudo $\mathrm{R}^{2}$ are calculated. The results are interpreted by calculating the change in probability of each variable to determine how likely the dependent variable is to change if the value of the predictor changed from the minimum to the maximum when other predictors are constant (Peng, Lee, \& Ingersoll, 2002).

The results show that all variable work and home interactions are strong predictors of employees' psychological condition as a unidimensional variable. NWHI has a significant negative association with employees' psychological condition $(\beta=-0,48$, SE $=0,14$, OR $=0,62 \mathrm{p}<0,001)$. This means that for every one-unit increase in NWHI, the psychological condition is likely to decrease by $0,38(38 \%)$ units. PHWI has a positive association on employees' psychological condition $(\beta=2,68, \mathrm{SE}=0,19, \mathrm{OR}=$ $14,54, p<0,001)$, and for every one-unit increase in PHWI, employees' psychological condition is likely to increase by 0,93 (93\%) units. However, the results show that PWHI does not have an expected sign in the model; hence, whether an employee has a low or high psychological condition could not be predicted by this 
Table 1 Participants with High and Low Psychological Conditions (N=2.288)

\begin{tabular}{|c|c|c|c|c|c|}
\hline Variables & Min & Max & Category & Frequency (n) & Percentage \\
\hline \multirow[t]{2}{*}{ Psychological Conditions - Meaningfulness } & 6 & 24 & Low & 242 & 10,6 \\
\hline & & & High & 2.046 & 89,4 \\
\hline \multirow[t]{2}{*}{ Psychological Conditions - Safety } & 3 & 12 & Low & 366 & 16 \\
\hline & & & High & 1.922 & 84 \\
\hline \multirow[t]{2}{*}{ Psychological Conditions - Availability } & 5 & 20 & Low & 474 & 20,7 \\
\hline & & & High & 1.814 & 79,3 \\
\hline \multirow[t]{2}{*}{ Psychological Conditions } & 14 & 56 & Low & 425 & 18,6 \\
\hline & & & High & 1.863 & 81,4 \\
\hline
\end{tabular}

Table 2 Correlations between the Variables

\begin{tabular}{|c|c|c|c|c|c|c|c|c|c|c|c|c|}
\hline & Variables & Means & SD & Median & 1 & 2 & 3 & 4 & 5 & 6 & 7 & 8 \\
\hline 1 & NWHI & 2,04 & 0,55 & 2,00 & & & & & & & & \\
\hline 2 & NHWI & 1,58 & 0,46 & 1,50 & $0,54 * *$ & & & & & & & \\
\hline 3 & PWHI & 2,92 & 0,50 & 3,00 & $-0,33 * *$ & $-0,26 * *$ & & & & & & \\
\hline 4 & PHWI & 3,19 & 0,49 & 3,20 & $-0,23 * *$ & $-0,28 * *$ & $0,60 * *$ & & & & & \\
\hline 5 & $\begin{array}{l}\text { Psychological } \\
\text { Conditions - } \\
\text { Meaningfulness }\end{array}$ & 20,62 & 3,17 & 21,00 & $-0,23 * *$ & $-0,32 * *$ & $0,41 * *$ & $0,61 * *$ & & & & \\
\hline 6 & $\begin{array}{l}\text { Psychological } \\
\text { Conditions - } \\
\text { Safety }\end{array}$ & 9,92 & 1,51 & 10,00 & $-0,35 * *$ & $-0,34 * *$ & $0,32 * *$ & $0,43 * *$ & $0,50 * *$ & & & \\
\hline 7 & $\begin{array}{l}\text { Psychological } \\
\text { Conditions - } \\
\text { Availability }\end{array}$ & 16,06 & 2,42 & 15,00 & $-0,17 * *$ & $-0,27 * *$ & $0,41 * *$ & $0,63 * *$ & $0,61 * *$ & $0,48 * *$ & & \\
\hline 8 & $\begin{array}{l}\text { Psychological } \\
\text { Conditions }\end{array}$ & 46,60 & 5,99 & 47,00 & $-0,28 * *$ & $-0,37 * *$ & $0,46^{* *}$ & $0,69 * *$ & $0,90 * *$ & $0,71 * *$ & $0,85 * *$ & \\
\hline
\end{tabular}

Note: $\mathrm{N}=2.288$

** All correlations are significant at 0,01 level (2-tailed)

Table 3 Result of the Logistic Regression Analysis

\begin{tabular}{|c|c|c|c|c|c|c|c|c|c|c|c|c|c|c|c|c|}
\hline \multirow[b]{2}{*}{ Variable } & \multicolumn{4}{|c|}{$\begin{array}{c}\text { Psychological } \\
\text { Conditions } \\
(\text { High=1, Low }=0)\end{array}$} & \multicolumn{4}{|c|}{$\begin{array}{c}\text { Psychological } \\
\text { Conditions- } \\
\text { Meaningfulness } \\
(\text { High }=1, \text { Low }=0)\end{array}$} & \multicolumn{4}{|c|}{$\begin{array}{c}\text { Psychological } \\
\text { Conditions - Safety } \\
(\text { High }=1, \text { Low }=0)\end{array}$} & \multicolumn{4}{|c|}{$\begin{array}{c}\text { Psychological } \\
\text { Conditions - } \\
\text { Availability } \\
(\text { High=1, Low }=0)\end{array}$} \\
\hline & $\beta$ & SE & OR & $p$ & $\beta$ & SE & OR & $p$ & $\boldsymbol{\beta}$ & SE & OR & $p$ & $\beta$ & SE & OR & $p$ \\
\hline NWHI & $-0,48$ & 0,14 & 0,62 & $* * *$ & $-0,31$ & 0,16 & 0,74 & 0,058 & $-0,89$ & 0,14 & 0,41 & $* * *$ & 0,12 & 0,13 & 1,13 & 0,342 \\
\hline NHWI & $-0,66$ & 0,16 & 0,52 & $* * *$ & $-0,73$ & 0,18 & 0,48 & $* * *$ & $-0,67$ & 0,15 & 0,51 & $* * *$ & $-0,35$ & 0,15 & 0,71 & $*$ \\
\hline PWHI & 0,39 & 0,17 & 1,48 & $*$ & 0,63 & 0,20 & 1,87 & $*$ & 0,18 & 0,16 & 1,20 & 0,272 & 0,26 & 0,15 & 1,30 & 0,09 \\
\hline PHWI & 2,68 & 0,19 & 14,54 & $* * *$ & 2,07 & 0,20 & 7,89 & $* * *$ & 1,29 & 0,16 & 3,64 & $* * *$ & 2,25 & 0,17 & 9,51 & $* * *$ \\
\hline $\begin{array}{l}\text { Cox \& Snell } \\
\text { R Squared }\end{array}$ & \multicolumn{4}{|c|}{0,226} & \multicolumn{4}{|c|}{0,138} & \multicolumn{4}{|c|}{0,126} & \multicolumn{4}{|c|}{0,169} \\
\hline $\begin{array}{l}\text { Nagelkerke's } \\
\text { pseudo-R } \\
\text { Squared }\end{array}$ & \multicolumn{4}{|c|}{0,226} & \multicolumn{4}{|c|}{0,138} & \multicolumn{4}{|c|}{0,126} & \multicolumn{4}{|c|}{0,169} \\
\hline $\begin{array}{l}\text { Hosmer \& } \\
\text { Lemeshow } \\
\text { Test }\end{array}$ & \multicolumn{4}{|c|}{$\begin{array}{c}x 2=585,2 \\
d f=2283, p<0,001\end{array}$} & \multicolumn{4}{|c|}{$\begin{array}{c}x 2=339,3 \\
d f=2283 p<0,001\end{array}$} & \multicolumn{4}{|c|}{$\begin{array}{c}x 2=307,7 \\
d f=2283, p<0,001\end{array}$} & \multicolumn{4}{|c|}{$\begin{array}{c}x 2=423,1 \\
d f=2283, p<0,001\end{array}$} \\
\hline
\end{tabular}

Note: $* \mathrm{p}<0,05$ level, $* * * \mathrm{p}<0,001$

variable.

NHWI and PWHI are found to be significant predictors of psychological meaningfulness.
NHWI has a significant negative association with psychological meaningfulness $(\beta=-0,73, \mathrm{SE}=0,18$, $\mathrm{OR}=0,48, \mathrm{p}<0,001)$, which means that for every one- 
unit increase in NWHI, psychological meaningfulness is likely to decrease by $0,32(32 \%)$ units. Meanwhile, PHWI has a positive association with psychological meaningfulness $(\beta=2,07, \mathrm{SE}=0,2, \mathrm{OR}=7,89, \mathrm{p}<$ $0,001)$, which means that for every one-unit increase in the PHWI, psychological meaningfulness is likely to increase by $0,88(88 \%)$ units. Nevertheless, NWHI does not have a significant association with psychological meaningfulness. Therefore, hypothesis 1 is fully supported, and hypothesis 4 is partially supported. The Pseudo $\mathrm{R}^{2}$ is 0,138 , which means that around $13,8 \%$ of the variance in psychological meaningfulness could be explained by the work-home interaction variables.

The results of the logistic regression analysis show that almost all variables of work-home interaction are found to be significant predictors for psychological safety except for the PWHI variable. Therefore, hypothesis 2 is fully supported, and hypothesis 5 is partially supported. The Pseudo $\mathrm{R}^{2}$ for this model is 0,126 ; in other words, around $12,6 \%$ of the variance in psychological safety could be explained by the workhome interaction variables.

Lastly, NHWI and PHWI have a significant and positive association with the psychological availability dimension. The PHWI shows a positive association with psychological availability $(\beta=2,25$, $\mathrm{SE}=0,17, \mathrm{OR}=9,51, \mathrm{p}<0,001)$. Here, for every one-unit increase in PHWI, psychological availability is likely to increase by $0,90(90 \%)$ units. Therefore, hypothesis 3 and hypothesis 6 are partially supported. The Pseudo $\mathrm{R}^{2}$ shows that $16,9 \%$ of the variance in psychological availability could be explained by the work-home interaction variables.

Overall, the results show that psychological conditions are best explained by NWHI, NHWI, PHWI, and PWHI. Employees who experienced lower NWHI and higher PHWI are more likely to have a better psychological condition. These results confirm previous findings that a negative influence more often arises from the work domain than the home domain, and the positive effects are more likely to arise from home than the work domain (Geurts et al., 2005). Therefore, home support (i.e., the support received from spouse or family members) and organization support are important in maintaining employees' psychological condition while working from home during the pandemic.

Negative home-work interactions and both positive work and home interactions are found to be significant predictors of psychological meaningfulness. This result confirms previous research that employees who experience negative home-work-home interactions are likely to experience less psychological meaningfulness at work (Rothmann \& Baumann, 2014). Based on job demand resource theory, if employees face excessive load from the work domain and lack sufficient resources to cope with it, they may be more likely to feel less meaningfulness.

Otherwise, positive experiences that happen at work spill over to the home domain and vice versa and promote employee psychological meaningfulness, safety, and availability (Jacobs, 2013; Rothmann \& Baumann, 2014). Work-life balance that takes advantage of the benefits of telecommuting (Grant, Wallace, \& Spurgeon, 2013; Maruyama \& Tietze, 2012) has also been shown to influence whether employees perceive their work as meaningful (Munn, 2013). Further, the employee will perceive their work as more meaningful and valuable because they have been able to keep their jobs and receive a full income, unlike many other employees who have lost their jobs and have suffered a reduction in their income during the pandemic. In addition, the present research is conducted in Indonesia, which has a collective culture that also affects employee behavior. As noted by Spector et al. (2017), in collectivist societies, work is seen as meaningful not only to oneself but also as a means of supporting a family. These factors may lead employees to perceive better psychological conditions while working from home during the pandemic.

The results of the logistic regression analysis show that almost all variables of work-home interaction are found to be significant predictors for psychological safety except the PWHI variable. It is reasoned that employees may also feel safer and less stressed while working from home, as they do not need to confront the hazards of commuting and potential exposure to a contagious virus (Giorgi et al., 2020). They may also experience a feeling of freedom and be more comfortable expressing themselves in the absence of direct and face-to-face supervision from their superiors and subordinates.

Lastly, negative home-work interactions and positive home-work interactions have a significant and positive association with the psychological availability dimension. According to Kahn's (1990) framework, individuals experiencing psychological availability can control and devote their physical, intellectual, and emotional energy, even when there are disturbances in their social systems. Similarly, in the present research, participants are able to be involved in every work activity even when faced with the difficult situation of balancing competing work and home demands while working from home. This could be because most participants in the present research are relatively young and highly educated, meaning they may have been more likely to have sufficient resources (e.g., physical, energy, and intellectual) to overcome distractions. Such individuals may be better able to use technology to manage their workload while working from home and may subsequently feel more ready and confident to engage with their work.

Results of the research contribute theoretically to the research on industrial and organizational psychology, especially in research on telework which is considered as an alternative working arrangement during the COVID-19 pandemic. The result provides insight into the factors that promote employees' psychological meaningfulness, safety, and availability in the context of working from home during the ongoing COVID-19 pandemic. Further, the result 
of the research can be used as a reference for future research related to the management of telework in organizations and identify any potential factor that serves as a resource to promote positive telework outcomes.

The research has some limitations. First, although the research utilizes a large sample, the results cannot be generalized to different types of organizations because participants originated from one organization. Thus, future research should be conducted across a variety of organizations. Second, the research uses cross-sectional and single sources to collect data which could potentially lead to common method bias (Spector, 2019). Therefore, several procedural remedies are used to minimize bias, such as randomizing the questionnaire items, protecting anonymity and confidentiality, and ensuring the participants that there are no right or wrong answers to encourage them to answer honestly. A statistical remedy is also conducted using Harman's single-factor test to check for the presence of common method variance (Podsakoff, MacKenzie, \& Podsakoff, 2012; Tehseen, Ramayah, \& Sajilan, 2017). The results show that the total variance explained by a single factor is $26,17 \%$. This means that there are $26,17 \%$ of all items loaded into one common factor. Since this result is under $50 \%$, it suggests that common method bias does not affect our research data (Podsakoff, MacKenzie, \& Podsakoff, 2012). Third, some items for psychological safety do not have satisfactory alpha Cronbach (internal consistency). It is observed that the safety scales only consisted of three items, which may have reduced Cronbach's $\alpha$ coefficient (Taber, 2018). Thus, further research should develop a measurement for psychological safety scales.

\section{CONCLUSIONS}

The research aims to investigate the work-home interaction factors that impact employee psychological conditions while working from home during the ongoing COVID-19 pandemic. Based on the results, it can be concluded that positive and negative experience that happens at work spill over to the home domain and vice versa, which could, in turn, impact on employee sense of meaningful, safety, and sense of having the physical, emotional, and psychological resources to perform tasks at work during working from home.

The research offers some implications for organizations and management to maintain employee psychological conditions due to working from home during the ongoing COVID-19 pandemic. First, to enhance meaningfulness, organizations should create an effective job design, adjust employees for particular work roles, and ensure that employees receive and understand the policy, what it means for their role, and what they need to do. Second, to foster psychological safety, leaders or managers organizations should build positive working from home (WFH) experience such as maintaining continuous communication with employees, showing their presence, and staying alert to signs of chronic stress on their teams. Lastly, to support employee psychological availability, organizations should support work-life balance, ensure sufficient recovery time, and not too overwhelm employees with excessive workload. Further, the organization should support their employees in establishing home workspaces, such as providing the right tech tool to facilitate efficient home working.

Data for the research were collected when the COVID-19 pandemic had just begun to emerge in Indonesia. In light of this, future research should be conducted to confirm the findings of the research and explore whether employees' psychological condition now differs because case numbers have increased sharply, and the government has implemented 'new normal' adaptations. The researchers also suggest investigating any possible moderators such as demands and resources in the work and home domain and including participants' marital status, as married and unmarried employees may have different roles and resources, which could, in turn, affect their psychological condition.

\section{REFERENCES}

Abrams, Z. (2020). Psychologists' advice for newly remote workers. Retrieved from https://www.apa.org/news/ apa/2020/03/newly-remote-workers.

APS (Australian Psychological Society). (2020). Maintaining employee engagement during COVID-19. Retrieved from https://www. psychology.org.au/getmedia/5c7bd7ac-7229-41fa867b-68a265fb237f/APS-COP-IS-COVID-19Employee-engagement-P1.pdf.

Atalan, A. (2020). Is the lockdown important to prevent the COVID-19 pandemic? Effects on psychology, environment, and economy-perspective. Annals of Medicine and Surgery, 56, 38-42. https://doi. org/10.1016/j.amsu.2020.06.010.

Cai, Z., Huang, Q., Liu, H., \& Wang, X. (2018). Improving the agility of employees through enterprise social media: The mediating role of psychological conditions. International Journal of Information Management, 38(1), 52-63. https://doi.org/10.1016/j. ijinfomgt.2017.09.001.

Carvalho, V. S., Chambel, M. J., Neto, M., \& Lopes, S. (2018). Does work-family conflict mediate the associations of job characteristics with employees' mental health among men and women? Frontiers in Psychology, 9, 1-12. https://doi.org/10.3389/ fpsyg.2018.00966.

Chong, S., Huang, Y., \& Chang, C. D. (2020). Supplemental material for supporting interdependent telework employees: A moderated-mediation model linking daily COVID-19 task setbacks to next-day work withdrawal. Journal of Applied Psychology, 105(12), 1408-1422. https://doi.org/10.1037/ap10000843. supp.

Demerouti, E., Bakker, A. B., \& Voydanoff, P. (2010). 
Does home life interfere with or facilitate job performance? European Journal of Work and Organizational Psychology, 19(2), 128-149. https:// doi.org/10.1080/13594320902930939.

Demerouti, E., Geurts, S. A. E., \& Kompier, M. (2004). Positive and negative work-home interaction: Prevalence and correlates. Equal Opportunities International, 23(1/2), 6-35. https://doi. org/10.1108/02610150410787837.

Fairlie, P. (2011). Meaningful work, employee engagement, and other key employee outcomes: Implications for human resource development. Advances in Developing Human Resources, 13(4), 508-525. https://doi.org/10.1177/1523422311431679.

Geurts, S. A. E., Taris, T. W., Kompier, M. A. J., Dikkers, J. S. E., Van Hooff, M. L. M., \& Kinnunen, U. M. (2005). Work-home interaction from a work psychological perspective: Development and validation of a new questionnaire, the SWING. Work and Stress, 19(4), 319-339. https://doi. org/10.1080/02678370500410208.

Giorgi, G., Lecca, L. I., Alessio, F., Finstad, G. L., Bondanini, G., Lulli, L. G., Arcangeli, G., \& Mucci, N. (2020). COVID-19-related mental health effects in the workplace: A narrative review. International Journal of Environmental Research and Public Health, 17(21), 1-22. https://doi.org/10.3390/ ijerph17217857/

Grant, C. A., Wallace, L. M., \& Spurgeon, P. C. (2013). An exploration of the psychological factors affecting remote e-worker's job effectiveness, well-being and work-life balance. Employee Relations, 35(5), 527 546. https://doi.org/10.1108/ER-08-2012-0059.

Hill, C., \& Blunn, L. (2018). Personality and work-home interaction among dual-earner couples in South Africa: Testing an actor-partner interdependence model. Journal of Psychology in Africa, 28(6), 435443. https://doi.org/10.1080/14330237.2018.15398 98.

Hosmer, D. W., \& Nils, L. H. (2002). Goodness-of-fit processes for logistic regression: Simulation results. Statistics in Medicine, 21(18), 2723-2738. https:// doi.org/10.1002/sim.1200.

ILO (International Labour Organization). (2020). ILO monitor: COVID-19 and the world of work. $1^{\text {st }}$ Edition. Retrieved from https://www.ilo.org/global/ about-the-ilo/WCMS_738753/lang--en/index.htm.

ITC (International Test Commision). (2017). International Test Commission guidelines for translating and adapting tests. Retrieved from https:/www. intestcom.org/files/guideline_test_adaptation_2ed. pdf.

Jacobs, H. (2013). An examination of psychological meaningfulness, safety, and availability as the underlying mechanisms linking job features and personal characteristics to work engagement. ProQuest Dissertations and Theses. Miami: Florida International University. https://doi.org/10.25148/ etd.FI13080518.

Jostell, D., \& Hemlin, S. (2018). After hours teleworking and boundary management: Effects on work- family conflict. Work, 60(3), 475-483. https://doi. org/10.3233/WOR-182748.

Kahn, W. A. (1990). Psychological conditions of personal engagement and disengagement at work. Academy of Management Journal, 33(4), 692-724. https://doi. org/10.5465/256287.

Kung, F. Y. H., Kwok, N., \& Brown, D. J. (2018). Are attention check questions a threat to scale validity? Applied Psychology, 67(2), 264-283. https://doi. org/10.1111/apps.12108.

Łaba, K., \& Geldenhuys, M. (2018). Positive interaction between work and home, and psychological availability on women's work engagement: A 'shortitudinal' study. SA Journal of Industrial Psychology, 44, 1-11. https://doi.org/10.4102/sajip. v44i0.1538.

Maruyama, T., \& Tietze, S. (2012). From anxiety to assurance: Concerns and outcomes of telework. Personnel Review, 41(4), 450-469. https://doi. org/10.1108/00483481211229375.

May, D. R., Gilson, R. L., \& Harter, L. M. (2004). The psychological conditions of meaningfulness, safety, and availability and the engagement of the human spirit at work. Journal of Occupational and Organizational Psychology, 77(1), 11-37. https:// doi.org/10.1348/096317904322915892.

Michael-Tsabari, N., Houshmand, M., Strike, V. M., \& Treister, E. D. (2020). Uncovering implicit assumptions: Reviewing the work-family interface in family business and offering opportunities for future research. Family Business Review, 33(1), 6489. https://doi.org/10.1177/0894486519899789.

Mostert, K. (2006). Work-home interaction as partial mediator between job resources and work engagement. Southern African Business Review, 10(2), 53-74. https://doi.org/10.1211/ijpp.15.3.0011.

Munn, S. L. (2013). Unveiling the work-life system: The influence of work-life balance on meaningful work. Advances in Developing Human Resources, 15(4), 401-417. https://doi. org/10.1177/1523422313498567.

Oakman, J., Kinsman, N., Stuckey, R., Graham, M., \& Weale, V. (2020). A rapid review of mental and physical health effects of working at home: How do we optimise health? BMC Public Health, 20(1), 1-14. https://doi.org/10.1186/s12889-020-09875-z.

Obrenovic, B., Jianguo, D., Khudaykulov, A., \& Khan, M. A. S. (2020). Work-family conflict impact on psychological safety and psychological well-being: A job performance model. Frontiers in Psychology, 11, 1-18. https://doi.org/10.3389/fpsyg.2020.00475.

Palumbo, R. (2020). Let me go to the office! An investigation into the side effects of working from home on work-life balance. International Journal of Public Sector Management, 33(6-7), 771-790. https://doi. org/10.1108/IJPSM-06-2020-0150.

Paulson, D., \& Leuty, M. E. (2016). Dispositional coping, personality traits, and affective style relating to conflict between work and family domains. Journal of Family and Economic Issues, 37(4), 519-539. https://doi.org/10.1007/s10834-015-9470-3. 
Peng, C. Y. J., Lee, K. L., \& Ingersoll, G. M. (2002). An introduction to logistic regression analysis and reporting. Journal of Educational Research, 96(1), 3-14. https://doi.org/10.1080/00220670209598786.

Podsakoff, P. M., MacKenzie, S. B., \& Podsakoff, N. P. (2012). Sources of method bias in social science research and recommendations on how to control it. Annual Review of Psychology, 63, 539-569. https:// doi.org/10.1146/annurev-psych-120710-100452.

Rothmann, S., \& Baumann, C. (2014). Employee engagement: The effects of work-home/home-work interaction and psychological conditions. South African Journal of Economic and Management Sciences, 17(4), 515-530. https://doi.org/10.4102/ sajems.v17i4.419.

Solís, M. S. (2016). Telework: Conditions that have a positive and negative impact on the work-family conflict. Academia Revista Latinoamericana de Administracion, 29(4), 435-449. https://doi. org/10.1108/ARLA-10-2015-0289.

Spector, P. E. (2019). Do not cross me: Optimizing the use of cross-sectional designs. Journal of Business and Psychology, 34(2), 125-137. https://doi.org/10.1007/ s10869-018-09613-8.

Spector, P. E., Cooper, C. L., Poelmans, S., Allen, T. D., O’Driscoll, M., Sanchez, J. I., Siu, O. L., Dewe, P., Hart, P., Lu, L., De Moraes, L. F. R., Ostrognay, G. M., Sparks, K., Wong, P., \& Yu, S. (2017). A cross-national comparative study of work-family stressors, working hours, and well-being: China and Latin America versus the anglo world. In International Human Resource Management: From Cross-Cultural Management to Managing a Diverse Workforce, (pp. 257-280). London: Routledge.

Taber, K. S. (2018). The use of Cronbach's Alpha when developing and reporting research instruments in Science education. Research in Science Education, 48(6), 1273-1296. https://doi.org/10.1007/s11165016-9602-2.
Tehseen, S., Ramayah, T., \& Sajilan, S. (2017). Testing and controlling for common method variance: A review of available methods. Journal of Management Sciences, 4(2), 142-168. https://doi.org/10.20547/ jms.2014.1704202.

Thulin, E., Vilhelmson, B., \& Johansson, M. (2019). New telework, time pressure, and time use control in everyday life. Sustainability (Switzerland), 11(11), 1-17. https://doi.org/10.3390/su11113067.

Vaziri, H., Casper, W. J., Wayne, J. H., \& Matthews, R. A. (2020). Changes to the work-family interface during the COVID-19 pandemic: Examining predictors and implications using latent transition analysis. Journal of Applied Psychology, 105(10), 1073-1087. https:// doi.org/10.1037/ap10000819.

Verweij, H., van Hooff, M. L. M., van der Heijden, F. M. M. A., Prins, J. T., Lagro-Janssen, A. L. M., van Ravesteijn, H., \& Speckens, A. E. M. (2017). The relationship between work and home characteristics and work engagement in medical residents. Perspectives on Medical Education, 6(4), 227-236. https://doi.org/10.1007/s40037-017-0364-y.

Vyas, L., \& Butakhieo, N. (2020). The impact of working from home during COVID-19 on work and life domains: An exploratory study on Hong Kong. Policy Design and Practice, 4(1), 1-18. https://doi. org/10.1080/25741292.2020.1863560.

WHO (World Health Organization). (2020). Mental health \& COVID-19. Retrieved from https://www.who.int/ teams/mental-health-and-substance-use/covid-19

WHO (World Health Organization). (2021). Weekly operational update on COVID-19. Retrieved from https://www.who.int/publications/m/item/weeklyupdate-on-covid-19---16-october-2020

Xiao, Y., Becerik-Gerber, B., Lucas, G., \& Roll, S. C. (2021). Impacts of working from home during COVID-19 pandemic on physical and mental well-being of office workstation users. Journal of Occupational and Environmental Medicine, 63(3), 181-190. https://doi.org/10.1097/JOM.0000000000002097. 